\section{Trends in serious ocular trauma in Scotland}

\begin{abstract}
Purpose To report trends in serious, sight-threatening ocular trauma in Scotland. Methods A prospective, population-based, observational study of patients with ocular trauma admitted to hospital in Scotland during a 12-month period (2008-2009), conducted through the British Ophthalmic Surveillance Unit. Data on circumstances of the injuries and visual outcomes were collected using protocols standardised to those from an earlier study (1991-1992) to allow direct comparisons over time.
\end{abstract}

Results In all, $0.3 \%$ of all emergency admissions in Scotland were for ocular trauma. Significant differences were observed between the time periods in where an injury occurred $(P=0.009)$ : a reduction of those occurring in a sports/leisure facility $(8.2 \%)$ and an increase in those occurring on the street (21.4\%). Assaults remained the most common cause of injury (31\%). Gender differences persisted with females more likely to have an injury from falls (OR $=8.67 ; 95 \% \mathrm{CI}: 2.41-31.49 ; P=0.002)$, or in the home $(\mathrm{OR}=5.40 ; 95 \% \mathrm{CI}: 1.69-17.16$; $P=0.009$ ), and less likely to have one in the workplace $(P=0.06)$. Poor visual outcome was associated with injuries occurring in the home $(\mathrm{OR}=4.33, P=0.047)$, in a public place $(\mathrm{OR}=6.25, P=0.047)$, and those caused by a fall (OR 42.75, $P<0.001$ ); or assault (OR 7.29, $P=0.019)$. Half of those with a poor outcome have no perception of light.

Conclusion Serious ocular trauma remains an infrequent, sight-threatening event, associated with significant monocular visual morbidity. The findings suggest a shift from corporate to personal responsibility for risk awareness, health, and safety. Eye (2015) 29, 611-618; doi:10.1038/eye.2015.7; published online 13 February 2015

\section{Introduction}

Ocular trauma is an unplanned, but potentially avoidable event, making those eye injuries that
P Desai ${ }^{1}$, DS Morris², DC Minassian ${ }^{3}$ and

CJ MacEwen ${ }^{4}$

are severe and sight-threatening of particular public health interest. The epidemiology of ocular trauma attracts a steady trickle of publications annually, but there are limitations in the information reported due to variations in the definition of trauma, sources of data, and differences in service provision. ${ }^{1-6}$ This makes comparisons difficult and examining trends over time even more challenging.

In addition much of the information and evidence available are from over a decade or more, representing valuable legacy data but posing limitations in their relevance and application to the current provision of health care and lifestyles, unless updated with contemporaneous data. ${ }^{1-6}$ Routinely available operational health data can provide useful information on patterns of activity relating to serious ocular trauma at both local and national levels. Data on the circumstance of an event relating to ocular trauma rely on bespoke collections, registries, or hospital-based series, and may be limited by their coverage or representation of the population affected. ${ }^{1-9}$

We report new information from this population-based study regarding the aetiology and outcome of serious ocular trauma in Scotland, identify temporal trends by comparing the findings to an earlier legacy study conducted in 1991-1992 (using the same methodology), 1,2 and add routinely available operational data to these studies to provide the national context in health service activity.

\section{Materials and methods}

The Scottish Ocular Trauma Studies were prospective, observational population-based studies. This paper reports new data from the 2008-2009 study and compares this with the 1991-1992 results. Cases were identified by active surveillance of serious eye injuries as a result of ocular trauma during 1991-1992, and then repeated in 2008-2009, using the same
${ }^{1}$ Moorfields Eye Hospital NHS Foundation Trust, London, UK

${ }^{2}$ Cardiff Eye Unit, University Hospital of Wales, Cardiff, UK

${ }^{3}$ Institute of Ophthalmology, University College London, London, UK

${ }^{4}$ University Department of Ophthalmology, Ninewells Hospital, Dundee, Scotland

Correspondence: P Desai, Moorfields Eye Hospital NHS Foundation Trust, City Road, London, EC1V 2PD, UK

Tel: +44 (0)20 7566 2039;

Fax: +44 (0)20 75662972.

E-mail: Parul.desai@

moorfields.nhs.uk.

Some of the material reported here has been presented at the Symposium on Ocular Trauma at the Oxford Ophthalmological Congress, in July 2013.

Received: 17 June 2014 Accepted in revised form: 22 December 2014 Published online: 13 February 2015 
standardised definitions and protocols for case identification and data collection. Whilst these have been reported, ${ }^{1,2,10}$ the details applicable to both studies are summarised here as follows:

- The study population for both studies was that of Scotland, representing the population at risk of injury during the study period.

- All ophthalmic departments in Scotland were eligible for inclusion in the study.

- An event was defined as 'an injury or wound to the eye or adnexae caused by external force or violence, which requires admission to hospital for observation or treatment'. All such new events occurring during the study period and admitted under the care of a Consultant Ophthalmologist were eligible for inclusion.

- Data collection for reporting an event was over a 12-month period from November 2008 to October 2009, (previously November 1991 to October 1992), and follow-up data for outcomes were collected for up to a year following the event or up to the time of discharge (whichever came first).

- Data collection for the 1991-1992 study involved a local coordinator and supervisor at each ophthalmic department for data collection on reporting, admission and follow-up of an event. ${ }^{1,2}$

- The 2008-2009 study was conducted through the processes established by the British Ophthalmological Surveillance Unit (BOSU), ${ }^{10,11}$ with ethical approval from the Newcastle and North Tyneside 1 Research Ethics Committee (Reference 08/H0906/70). Following notification of an event to BOSU, specific study forms were used to collect data on the demographic characteristics of patients, the type of injury, cause (or activity) of injury, and the place (or setting) in which it was sustained; together with details on the process of care provided, clinical management on admission, and follow-up in outpatients; at discharge from ophthalmic care and for reporting a tertiary referral at any stage. Reminders were sent at regular intervals for outstanding data returns.

Mid-2009 population estimates for Scotland were obtained from the General Register Office for Scotland (2010), and for the earlier period the previously reported mid-1991 estimates were used.,12

A blinding outcome was defined as final visual acuity worse than 6/60 that was attributable to the eye injury. A poor visual outcome was defined as final visual acuity worse than 6/12, attributable to the eye injury (and as such includes blinding outcome). Final visual acuity was that recorded at 12 months after the eye injury, or earlier if discharged from eye care.
Routine hospital activity data from the Scottish Morbidity Records (SMR01) on admission and discharge were obtained from the Information Services Division (ISD) Scotland, to describe the patterns of emergency ocular trauma admissions in Scotland from the decade preceding the study up to 2011. The following ICD-10 diagnostic codes for ocular trauma were used: S00.1, S00.2, S01.1, S02.3, S04.0, S04.1, S04.2, S04.4, S05.0, and S05.1-S05.9.

The main findings of the 2008-2009 study are presented as relative frequency distributions of injury characteristic (type, place, and cause of injury) in relation to age group and sex. These provide the conditional probabilities of an injury displaying the characteristic under consideration, among those injured, allowing comparisons, and profiles of injury characteristics in subgroups, defined by age and sex. Fisher's exact two-sided $P$-values were computed for comparison of proportions in frequency distributions, and 'exact' methods based on the binomial distribution were used to calculate $95 \%$ confidence intervals (CIs) for a proportion. Crude associations between gender and injury characteristics were assessed through estimation of odds ratios (ORs), but where this was not possible owing to zero frequencies, Fisher's exact two-sided $P$-values are presented. Logistic regression was used to estimate ORs as a measure of association between poor visual acuity outcome and various features of the eye injury (type, place, and mechanism). Data were analysed by using Stata software, version 9 (StataCorp, College Station, TX, USA).

No further analyses are presented for the 1991-1992 legacy study. The methods that were employed have been reported elsewhere, ${ }^{1,2}$ and the findings are presented here for comparison with the current study, where appropriate.

\section{Results}

One hundred and two patients with ocular trauma were admitted to hospitals in Scotland, under the care of a Consultant Ophthalmologist, during the 12-month period November 2008 to October 2009. Of the records returned, at least $90 \%$ had complete data collection on all items, and final visual acuity data were available for 92 patients. There was a reduction in the number of patients admitted between the study periods from 415 in 1991-1992 to 102 in 2008-2009.1,2 Only one patient was admitted for bilateral injury (1\%), and these events remained infrequent. ${ }^{2}$

Consultant response to the BOSU reporting system was $77.1 \%$. As previously, good geographic coverage was achieved with all ophthalmic departments in Scotland participating in the studies. 


\section{Population change between 1992 and 2009}

The population of Scotland increased by 94000 persons (52797 males and 41203 females) from mid-1991 to mid-2009. The proportion of females in the population showed a decline in 2009 in persons aged 75 years and older, with little or no change in the younger age groups. Females made up $52 \%$ of the population at both time periods.

\section{Routine hospital activity data}

In 2008-2009, 0.3\% of all emergency admissions in Scotland were those having a diagnosis of ocular trauma. It has remained around this level for the preceding decade and up to 2011, with some intervening fluctuations. Of these emergency ocular trauma admissions, there has been a gradual decrease in the proportion admitted under the care of a Consultant Ophthalmologist, from $18.3 \%$ in 1998 to $13.6 \%$ in 2009, and $11.2 \%$ in 2011 (Table 1).

\section{Age and gender distribution}

Eighty-five percent of patients were male (similar to 1992 when $83 \%$ were male). Females were substantially older, with the difference in mean age being 20.26 years $(95 \%$ CI: $9.32-31.19, P=0.004$. $42 \%$ of admissions were in the 15-34-year age group, and of these $95 \%$ were males. Similarly in 1992, admissions were predominantly male patients, with $45 \%$ of all admissions in the 15-34-year age group (Table 2).

\section{Type of injury}

Blunt injuries remain the most common type of injury sustained $(41 \%)$, followed by penetrating injuries without an intraocular foreign body, (37\%). Previously, these accounted for 56 and 23\% of injuries, respectively, with significant differences in the overall frequency distribution for type of injury (Fisher's exact $P=0.01$; Table 3A).

\section{Place of injury}

The home was the most frequent place for an injury to occur $(30.6 \%)$, followed by the workplace $(20.4 \%)$, similar to previous findings. There was a significant difference in the overall frequency distribution over the two time periods, most notably in the observed increase in frequency of injuries occurring on the street, and a reduction in those occurring in a sports or leisure facility (Fisher's exact $P=0.009$; Table 3B).

Significant gender differences in the frequency distribution by place of injury were also seen (Fisher's exact $P=0.008$ ). Compared with males, females were more likely to have had the injury at 'Home' (OR 5.40; 95\% CI: 1.69-17.16; Fisher's exact $P=0.009)$. No injury events were observed for females at 'Work', suggesting that compared with males, females were less likely to

Table 1 Emergency ocular trauma admissions; Scotland, years 1998-2011

\begin{tabular}{cccccc}
\hline & $\begin{array}{c}\text { All } \\
\text { emergency } \\
\text { Ydmissions (N) }\end{array}$ & $\begin{array}{c}\text { Ocular trauma (OT) } \\
\text { emergency } \\
\text { admissions (n) }\end{array}$ & $\begin{array}{c}\text { OT emergency admissions } \\
\text { as a \% of all } \\
\text { emergency admissions }\end{array}$ & $\begin{array}{c}\text { OT emergencies } \\
\text { admissions under } \\
\text { ophthalmic specialty (n) }\end{array}$ & $\begin{array}{c}\% \text { Of OT emergency } \\
\text { admissions under } \\
\text { ophthalmic specialty }\end{array}$ \\
\hline 1998 & 466734 & 1793 & 0.38 & 328 & 18.3 \\
1999 & 472001 & 1600 & 0.34 & 308 & 19.3 \\
2000 & 481079 & 1538 & 0.32 & 294 & 19.1 \\
2001 & 480568 & 1622 & 0.34 & 253 & 15.6 \\
2002 & 474563 & 1598 & 0.34 & 249 & 15.6 \\
2003 & 481615 & 1540 & 0.32 & 244 & 15.8 \\
2004 & 482742 & 1441 & 0.30 & 234 & 16.2 \\
2005 & 500385 & 1513 & 0.30 & 256 & 16.9 \\
2006 & 524339 & 1461 & 0.28 & 241 & 16.1 \\
2007 & 537105 & 1582 & 0.29 & 217 & 11.7 \\
2008 & 535635 & 1837 & 0.34 & 162 & 13.1 \\
2009 & 530108 & 1592 & 0.30 & 193 & 13.6 \\
2010 & 539108 & 1605 & 0.30 & 0.1 \\
2011 & 550864 & 1728 & 0.31 & & 11.2 \\
\hline
\end{tabular}

Source: ISD, SMR01; Ref: IR2013-01326.

Notes: 1. These statistics are derived from data collected on discharges from non-obstetric and non-psychiatric hospitals (SMR01) in Scotland. Only patients treated as inpatients or day cases are included.

2. The unit of analysis is Episode based. Only patients treated as inpatients or day cases are included. An SMR01 episode is generated when a patient is discharged from hospital but also when a patient is transferred between hospitals, significant facilities, specialties or to the care of a different consultant. 3. Ocular Trauma Admissions are defined by ICD10 codes; S001, S002, S011, S023, S040, S041, S042, S044, S050, S051-S059. 
Table 2 Age and gender distribution of patients with ocular trauma admitted to hospital in Scotland

\begin{tabular}{|c|c|c|c|c|c|c|c|c|}
\hline & \multicolumn{2}{|c|}{ Age group-years, $\mathrm{n}($ row \%) } & \multirow[b]{2}{*}{$25-34$} & \multirow[b]{2}{*}{$35-44$} & \multirow[b]{2}{*}{$45-54$} & \multirow[b]{2}{*}{$55-64$} & \multirow[b]{2}{*}{65 and over } & \multirow[b]{2}{*}{ All } \\
\hline & $0-14$ & $15-24$ & & & & & & \\
\hline \multicolumn{9}{|l|}{ 2008-2009 } \\
\hline Males $^{\mathrm{a}}$ & $8(9.2)$ & $18(20.7)$ & $23(26.4)$ & $12(13.8)$ & $8(9.2)$ & 11 (12.6) & $7(8.1)$ & $87(85 \%)$ \\
\hline Females $^{\mathrm{a}}$ & $1(6.7)$ & $0(0)$ & $2(13.3)$ & $1(6.7)$ & $4(26.6)$ & $1(6.7)$ & $6(40)$ & $15(15 \%)$ \\
\hline All & $9(8.8)$ & $18(17.7)$ & $25(24.5)$ & $13(12.7)$ & $12(11.8)$ & $12(11.8)$ & $13(12.7)$ & 102 \\
\hline \multicolumn{9}{|l|}{ 1991-1992 } \\
\hline Males & $59(17.5)$ & $88(26)$ & $75(22.7)$ & $55(16)$ & $33(9.8)$ & $17(5)$ & $11(3)$ & $338(84 \%)$ \\
\hline Females & $26(38.8)$ & $10(14.9)$ & $10(14.9)$ & $3(4.5)$ & $3(4.5)$ & $2(3)$ & $13(19.4)$ & $67(16 \%)$ \\
\hline All & $85(21)$ & $98(24.2)$ & $85(21)$ & $58(14.3)$ & $36(8.9)$ & $19(4.7)$ & $24(5.9)$ & 405 \\
\hline
\end{tabular}

${ }^{\text {a }}$ Comparing age distribution between males and females in 2009: Fisher's exact $P=0.014$.

Table 3A Circumstances of ocular injury in patients admitted to hospital in Scotland $-n$ (row\%). TYPE of Injury

\begin{tabular}{|c|c|c|c|c|c|c|c|}
\hline & Blunt & Penetrating- no IOFB & Penetrating-with IOFB & Chemical burn & Thermal burn & Other & All \\
\hline \multicolumn{8}{|l|}{ 2008-2009 } \\
\hline Males $^{\mathrm{a}}$ & $33(37.9)$ & $35(40.2)$ & $9(10.3)$ & $2(2.3)$ & $1(1.2)$ & $7(8.1)$ & 87 \\
\hline Females $^{\mathrm{a}}$ & $9(60)$ & $3(20)$ & $0(0)$ & $0(0)$ & $0(0)$ & $3(20)$ & 15 \\
\hline $\mathrm{All}^{\mathrm{b}}$ & $42(41)$ & $38(37)$ & $9(9)$ & $2(2)$ & $1(1)$ & $10(10)$ & 102 \\
\hline \multicolumn{8}{|l|}{ 1991-1992 } \\
\hline $\mathrm{All}^{\mathrm{b}}$ & $226(56)$ & $93(23)$ & $30(7)$ & $27(7)$ & $4(1)$ & $26(6)$ & 406 \\
\hline
\end{tabular}

${ }^{a}$ Comparing 'type of injury' distribution between males and females in 2009 : Fisher's exact $P=0.216$.

${ }^{\mathrm{b}}$ Comparing the overall frequency distributions for Type of Injury in $1991 \& 2009$ Fisher's exact $P=0.010$.

Table 3B Circumstances of ocular injury in patients admitted to hospital in Scotland $-n$ (row\%). PLACE of Injury

\begin{tabular}{|c|c|c|c|c|c|c|c|}
\hline & Work & Home & School & Street & Sport/leisure facility & Other ${ }^{\mathrm{a}}$ & All \\
\hline \multicolumn{8}{|l|}{ 2008-2009 } \\
\hline Males ${ }^{\mathrm{b}}$ & $20(23.8)$ & $21(25)$ & $1(1.2)$ & $19(22.6)$ & $5(6)$ & $18(21.4)$ & 84 \\
\hline Females $^{\mathrm{b}}$ & $0(0)$ & $9(64.3)$ & $0(0)$ & $2(14.3)$ & $3(21.4)$ & $0(0)$ & 14 \\
\hline All $^{c}$ & $20(20.4)$ & $30(30.6)$ & $1(1)$ & $21(21.4)$ & $8(8.2)$ & $18(18.4)$ & 98 \\
\hline \multicolumn{8}{|l|}{ 1991-1992 } \\
\hline All ${ }^{\mathrm{C}}$ & $81(19.5)$ & $126(30.4)$ & $16(3.9)$ & $38(9.1)$ & $66(15.9)$ & $88(21.2)$ & 415 \\
\hline
\end{tabular}

Four patients with unknown place of injury (one female and three males) excluded from the table.

${ }^{\text {a } I n c l u d e s ~ ' P u b l i c ~ P l a c e ' ~} n=10$.

${ }^{\mathrm{b}}$ Comparing 'place of injury' distribution between males and females in 2009: Fisher's exact $P=0.008$.

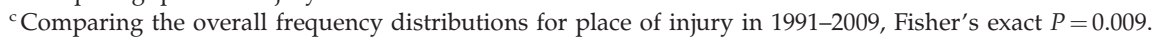

Table 3C Circumstances of ocular injury in patients admitted to hospital in Scotland- $n$ (row\%). CAUSE of Injury

\begin{tabular}{|c|c|c|c|c|c|c|c|}
\hline & Machinery/tools ${ }^{\mathrm{a}}$ & Assault & Falls & Vehicle accident & Chemical injury & Other & All \\
\hline \multicolumn{8}{|l|}{$2008-09^{\mathrm{b}}$} \\
\hline Males & $21(25)$ & 29 (34.5) & $6(7.1)$ & $4(4.8)$ & $3(3.6)$ & $21(25)$ & 84 \\
\hline Females & $0(0)$ & $2(13.3)$ & $6(40)$ & $0(0)$ & $0(0)$ & 7 (46.7) & 15 \\
\hline All $^{c}$ & $21(21.2)$ & 31 (31.3) & $12(12.1)$ & $4(4)$ & $3(3)$ & $28(28.3)$ & 99 \\
\hline \multicolumn{8}{|l|}{ 1991-92 } \\
\hline $\mathrm{All}^{\mathrm{c}}$ & $100(24.1)$ & $91(21.9)$ & $26(6.3)$ & $13(3.1)$ & $17(4.1)$ & $168(40.5)$ & 415 \\
\hline
\end{tabular}

${ }^{a}$ Includes hammering.

${ }^{\mathrm{b}}$ Comparing 'place of injury' distribution between males and females in 2009: Fisher's exact $P=0.001$.

${ }^{\circ}$ Comparing the overal frequency distributions for mechanism of injury in 1991-2009, Fisher's exact $P=0.069$. 
have had the injury occurring at 'Work' (Fisher's exact $P=0.06)$.

\section{Cause of injury}

Overall, 'Assault' (31.3\%) was the most common cause of injury, followed by 'Machinery/Tools' (21.2\%). This order remained unchanged in males, but in females, the commonest cause of injury was a 'Fall' $(40 \%)$, and no injuries were caused by 'Machinery/Tools'. The gender difference in the overall distribution by cause of injury was significant (Fisher's exact $P=0.001$ ).

Females were more likely to have had 'Fall' as the cause of their injury, compared with males $(\mathrm{OR}=8.67$; 95\% CI: 2.41-31.49; Fisher's exact $P=0.002$ ), and less likely to have an injury caused by 'Machinery/Tools' (Fisher's exact two-sided $P=0.036$ ).

In 2009, the proportion of injuries due to 'Machinery/ Tools' among injuries at home was lower than that at work (25\% and 65\%, respectively), whereas in 1992, the proportion of these injuries were $46 \%$ and $52 \%$, respectively. The chemical injuries reported occurred at work.

No significant difference in the overall frequency distribution for the mechanism of injury over the two time periods was demonstrated (Fisher's exact $P=0.069$; Table 3C).

Protective eye wear was not considered to be applicable in the majority of injuries $(61 \%, n=62)$. Four patients were wearing refractive correction (three glasses and one contact lenses). When applicable protective eye wear was worn by $5 \%(n=1 / 20)$ patients at the time of injury. In the earlier study, protective eye wear when applicable was worn by $9.5 \%(7 / 74)$ of patients.

\section{Blinding and poor visual outcome}

Of the 92 patients with valid final visual acuity records, $32(34.8 \%, 95 \%$ C.I $25.15-45.42 \%)$, had a poor visual outcome attributable to the injury. Half of the patients with poor visual outcome $(n=16 / 32)$ had no perception of light in the injured eye, which was similar to earlier findings $(n=12 / 24){ }^{1}$

Type: No significant associations were found between 'Type of injury' and with either poor visual outcome or blinding outcome.

Place: The observed proportion of poor visual acuity outcome in injuries at 'Work' (17\%) was lower than that in every one of the other places of injury, apart from 'School' that was not assessed further owing to small numbers. Poor visual outcome occurred in $46 \%$ of injuries sustained in the Home, in $41 \%$ of those that occurred in the Street, in $56 \%$ of those occurring in a
Public Building, and in 25\% of injuries that took place in a Sports or Leisure Facility.

Findings from logistic regression are summarised in Table 4. The proportion with poor visual outcome when injuries occurred at 'Home', or in a 'Public Building' was significantly higher than those occurring at 'Work' $(\mathrm{OR}=4.33, P=0.047$; and $\mathrm{OR}=6.25, P=0.047$,

respectively. There were no other significant differences and adjustment for age or gender made no material difference to the findings.

Results for blinding outcome were similar to that of poor visual outcome, but the observed associations were not statistically significant.

Cause: The highest proportion of poor visual outcome occurred in injuries due to a 'Fall' $(83 \%, n=10 / 12)$ followed by those due to an 'Assault' (46\%, $n=12 / 26)$, and those caused by machinery and tools $(13 \%, n=2$ / 15). Collectively $77 \%(n=24 / 31)$ of cases of poor visual outcome occurred in injuries caused by these categories.

Table 4 Poor visual outcome-association with place and cause of injury. Output from logistic regression

\begin{tabular}{|c|c|c|c|}
\hline & $\begin{array}{l}\text { Odds } \\
\text { ratio }\end{array}$ & P-value & $\begin{array}{c}95 \% \\
\text { Confidence } \\
\text { interval for } \\
\text { odds ratio }\end{array}$ \\
\hline \multicolumn{4}{|l|}{ Place of injury } \\
\hline \multicolumn{4}{|l|}{ Poor VA outcome in: } \\
\hline Work (referent) & 1.00 & & \\
\hline Home & 4.33 & 0.047 & $1.02-18.38$ \\
\hline Street & 3.50 & 0.118 & $0.73-16.85$ \\
\hline Public building & 6.25 & 0.047 & $1.03-38.08$ \\
\hline Sport/leisure facility & 1.67 & 0.621 & $0.22-12.62$ \\
\hline Other & 1.67 & 0.621 & $0.22-12.62$ \\
\hline \multicolumn{4}{|l|}{ Blinding outcome in: } \\
\hline Work (referent) & 1.00 & & \\
\hline Home & 2.78 & 0.17 & $0.64-11.97$ \\
\hline Street & 1.54 & 0.613 & $0.29-8.18$ \\
\hline Public building & 2.50 & 0.337 & $0.39-16.05$ \\
\hline Sport/leisure facility & 1.67 & 0.621 & $0.22-12.62$ \\
\hline Other & 1.67 & 0.621 & $0.22-12.62$ \\
\hline \multicolumn{4}{|l|}{ Cause of injury } \\
\hline \multicolumn{4}{|l|}{ Poor VA outcome in: } \\
\hline Machinery/tools ${ }^{\text {a }}$ (referent) & 1.00 & & \\
\hline Fall & 42.50 & $<0.001$ & $5.15-350.50$ \\
\hline Assault & 7.29 & 0.019 & $1.39-38.15$ \\
\hline Other & 2.38 & 0.314 & $0.44-12.87$ \\
\hline \multicolumn{4}{|l|}{ Blinding outcome in: } \\
\hline $\begin{array}{l}\text { Machinery /tools }{ }^{\mathrm{a}} \\
\text { (referent) }\end{array}$ & 1.00 & & \\
\hline Fall & 11.90 & 0.009 & $1.85-76.83$ \\
\hline Assault & 3.13 & 0.189 & $0.57-17.18$ \\
\hline Other & 2.38 & 0.314 & $0.44-12.87$ \\
\hline
\end{tabular}

School not assessed due to small numbers.

${ }^{\text {a }}$ Includes hamering. 
Findings from logistic regression are summarised in Table 4. The proportion of injuries from a 'Fall' resulting in a poor or blinding visual outcome was significantly higher than in the other categories. (OR for poor visual outcome from 'Fall' $=42.5$, 95\% CI 5.15-350.50, $P=<0.001$; and OR for blinding outcome from 'Fall' $=11.9,95 \%$ CI 1.85-76.83, $P=0.009$ ). The proportion of injuries from an assault having poor visual outcome was significantly higher than those from machinery and tools (OR $=7.29$, 95\% CI 1.39-38.15, $P=0.019)$. Adjustment for age or gender made no material difference to the findings.

\section{Discussion}

These population-based data collected prospectively, in real-life clinical settings, in two time periods serve to describe some differences in the pattern of serious ocular trauma presenting to a specialist Ophthalmic Department in the NHS in Scotland.

The standardised, prospective, case collection system employed has been shown to be a robust and pragmatic approach for identifying cases of interest in routine practice without introducing any significant systematic bias. 1,2,10,11 The completeness of reporting in the recent study operating through the BOSU was consistent with those previously reported from the Unit. ${ }^{11,13}$

The aging trend in the population of Scotland over the time period reflects that observed across all of the UK devolved nations, with females accounting for $51-52 \%$ of the respective populations, and can be considered to be applicable to the UK as a whole. ${ }^{14,15}$

Males continue to account for the vast majority of emergency admissions for ocular trauma, particularly those in 15-34-year age group, and this has been consistently reported for many years from hospital and population-based studies and surveillance systems. ${ }^{3-9}$ The observed gender differences around the circumstance of an ocular trauma event also persist. Compared with males, females are more likely to have an injury in the home and as a result of a fall, and less likely to have an injury in the workplace. These may reflect differences between males and females, with respect to their daily activities that may be risk factors for injury, as well as duration of exposure to these risk factors.

There was a significant change in the distribution of where an injury took place. Although the home remains the most common place for an injury to occur and the proportion of those occurring in the workplace remain unchanged, the observed difference in the overall distribution was influenced by an increase in frequency of injuries on the street and a decrease in those taking place in a sports of leisure facility. Machinery and tools, assault, and falls remain the major causes for an ocular injury.

As reported here, serious ocular trauma is predominantly a unilateral event. ${ }^{2,6}$ It is associated with significant monocular visual morbidity, and particularly with those injuries occurring in the home or a public place (other than a sports or leisure facility) and those caused by a fall or an assault. This would not otherwise be evident as monocular sight loss is not certifiable and therefore not captured in national certification and registration of sight impairment in the UK. Certification of severe sight impairment (ie, binocular sight loss) in England and Wales for all ages, attributable to injuries and accidents has fallen from $0.3 \%$ (36/13788 of all such certifications) in 1999-2000 to $0.09 \%$ (7/8173) in 2007-2008. ${ }^{16,17}$ The circumstances of the injury or accident causing certifiable sight loss are not available.

The findings reported are consistent with wider national trends in accidents and injuries. Accidents (45\%) in the home are caused by falls, ${ }^{18}$ and $35 \%$ of falls requiring emergency admissions to hospital occur in the home. ${ }^{19}$ Accidents and falls prevention in the home remain the focus of mainstream public health interventions, ${ }^{20}$ and their implementation is likely to have direct (albeit unplanned) benefit and relevance to the prevention of serious and potentially sightthreatening ocular trauma. Corporate responsibility for health and safety in the workplace, sports and leisure facilities, and other public places in the UK is covered by legislation, statutory instruments, and guidance for both employers and employees. ${ }^{21}$ Over the past decade between 2003 and 2013, the proportion of all injuries occurring at work has remained relatively stable at about $20 \%$ (reflecting the pattern seen for eye trauma), and self-reported and nonfatal injuries have fallen by one third. $^{22}$

Levels of physical activity in Scotland remain fairly stable. Between 1998 and 2011, about 45\% of men and $33 \%$ of women in Scotland reported meeting the recommended levels of moderate physical activity for adults, similar to the current levels of activity in England. ${ }^{23,24}$ Sports and structured exercise were the most popular types of physical activity for $54 \%$ men and $45 \%$ women. ${ }^{23,24}$ It may be reasonable to assume that some proportion of this structured exercise took place in a sports or leisure facility, such that implementation of health and safety legislation would have had some influence in reducing risk of any potential injury, including an ocular injury.

Overall, these findings may indicate a shift from corporate responsibility for health and safety towards personal responsibility for awareness of risk and making informed choices for prevention of injuries, including serious eye injuries. 
Ocular trauma continues to account for a small proportion of all emergency admissions- $0.3 \%$ in Scotland and about $0.25 \%$ in England. ${ }^{25}$ The proportion of these admitted under the care of a Consultant Ophthalmologist has been falling steadily over more than a decade to $11 \%$ in 2011-2012 (Table 1). Similarly in England for 2011-2012 this proportion was 10.5\% (personal communication, Health and Social Care Information Centre, Leeds, 2013, for direct analysis of Hospital Episode Statistics 2011-2012). ${ }^{25}$ This may reflect a combination of changes in practice (criteria for admission and clinical management), as well as service organisation and delivery in the NHS.

As indicated by these routine health service activity data, the majority of emergency admissions for ocular trauma have been, and continue (increasingly), to be managed primarily by other clinical specialties. These admissions may be associated with polytrauma of varying severity requiring multiprofessional (including ophthalmic) care for example, about $6-7 \%$ of patients with major trauma also have an ocular injury. ${ }^{26,27}$ Given the case definitions used in this (and the earlier legacy) study, no cases of polytrauma or major trauma were included. Nevertheless their needs should not be overlooked in any review or reconfiguration of emergency services to ensure that timely specialist ophthalmic care remains both accessible and available, and that the implications for training and maintenance of competencies are also considered.

We have previously reported a threefold reduction in risk of a poor visual outcome over the time periods covered by these two studies. ${ }^{10}$ Although neither of the studies was designed to answer the likely explanation for this, it is possible that factors, such as the long-term impact of health and safety legislation combined with changes in clinical management, service delivery, and organisation may also be influencing the differences observed.

\section{Summary}

What was known before

- There are significant gender differences in hospital admissions for serious ocular trauma. Nearly half of all admissions are 15-34 years of age, almost exclusively males (over 90\%).

- In the population studied, serious ocular trauma most commonly occurs in the home.

\section{What this study adds}

- Ocular trauma is associated with significant monocular visual morbidity, particularly with injuries occurring in the home or a public place (other than a sports or leisure facility) and those caused by a fall or an assault.

- An apparent shift from corporate to personal responsibility for awareness of risk, health, and safety for prevention of serious ocular trauma has been highlighted that is consistent with the wider national trends in accidents and injuries.

- The proportion of all serious ocular trauma admitted under the care of a Consultant Ophthalmologist is decreasing. Availability of timely specialist care should be considered in any reconfiguration of emergency services.

\section{Conflict of interest}

The authors declare no conflict of interest.

\section{Acknowledgements}

We thank Tracy Sparey-Ophthalmology Secretary, University of Dundee, for project administration. Barny Foot, British Ophthalmic Surveillance Unit (BOSU), Royal College of Ophthalmologists, London, UK. Laura Marchbank, Senior Information Analyst, Information Services Division (ISD). NHS National Services Scotland, for SMR01 data. Chris Dew, Senior Information Analyst, Health and Social Care Information Centre, Leeds, for HES data interpretation. We also thank the Scottish Ophthalmological Club and the whole Scottish. Ophthalmic community for their support, contribution, and enthusiasm especially: A Agrawal, D Assheton, HR Atta, A Azura-Blanco, PS Baines, CW Barras, G Bedford, H Bennett, N Boyle, P Cauchi, C Cobb, G Cormack, A Cox, HC Devlin, J Ellis, L Esakowitz, A Ferguson, AI Fern, B Fleck, A Gaskell, ND George, J Gillen, D Grierson, M Gupta, H Hammer, IT Hanna, S Hewick, W Ho, F Imrie, P Kearns, J Kerr, L Kuffova, T Leslie, N Lois, CJ MacEwen, JA MacRae, S Madill, D Mansfield, DM Montgomery, J Murdoch, H Murgatroyd, RI Murray, SB Murray, A Pyott, A Reddy, C Scott, A Singh, JA Scott, J Singh, C Styles, S Sutherland, K Thompson, RP Savides, MG Stoddart, DRA Wardrop, C Weir, J Welch, K Wong, WW Wykes, D Yorston, and YY Zhang. WH Ross Foundation (Scotland).

\section{References}

1 Desai P, MacEwen CJ, Baines P, Minassian DC. Incidence of cases of ocular trauma admitted to hospital and incidence of blinding outcome. Br J Ophthalmol 1996; 80: 592-596.

2 Desai P, MacEwen CJ, Baines P, Minassian DC. Epidemiology and implications of ocular trauma admitted to hospital in Scotland. J Epidemiol Community Health 1996; 50: 436-441.

3 Schein OD, Hibberd PL, Shingleton BJ, Kunzweiler T, Frambach DA, Seddon JM et al. The spectrum and burden of ocular injury. Ophthalmology 1988; 95(3): 300-305.

4 Katz J, Tielsch JM. Lifetime prevalence of ocular injuries from the Baltimore Eye Survey. Arch Ophthalmol 1993; 111(11): 1564-1568. 
5 MacEwen CJ. Eye injuries: a prospective survey of 5671 cases. Br J Ophthalmol 1989; 73(11): 888-894.

6 Kuhn F, Morris R, Witherspoon CD, Mann LR. Epidemiology of blinding trauma in the United States eye injury registry. Ophthalmic Epidemiology 2006; 13: 209-216.

7 McGwin G, Xie A, Owsley C. Rate of eye injury in the United States. Arch Ophthalmol 2005; 123: 970-976.

8 McGwin Jr, G, Owsley C. Incidence of emergency department-treated eye injury in the United States. Arch Ophthalmol 2005; 123(5): 662-666.

9 McGwin Jr, G, Hall TA, Xie A, Owsley C. Trends in eye injury in the United States, 1992-2001. Invest Ophthalmol Vis Sci 2006; 47: 521-527.

10 Morris DS, Willis S, Minassian D, Foot B, Desai P, MacEwen CJ. The incidence of serious eye injury in Scotland: a prospective study. Eye 2014; 28: 34-40.

11 Foot B, Stanford M, Rahi J, Thompson J. The British Ophthalmological Surveillance Unit: an evaluation of the first 3 years. Eye 2003; 17: 9-15.

12 The Directorate of Information Services, Information and Statistics Division, National Health Service in Scotland, Management Executive.

13 Foot BG, Stanford MR. Questioning questionnaires. Eye 2001; 15: 693-694.

14 ONS Population Estimates for UK, England and Wales, Scotland and Northern Ireland, mid 2009. http:/ /www. ons.gov.uk/ons/publications/re-reference-tables.html? edition=tcm\%3A77-213645 (accessed 4 February 2015).

15 ONS Population Estimates for UK, England and Wales, Scotland and Northern Ireland, Mid-1991 to Mid-2000 Local Authority Population Studies. http://www.ons.gov.uk/ ons/rel/pop-estimate/population-estimates-for-ukengland-and-wales-scotland-and-northern-ireland/ mid-1991-to-mid-2000-local-authority-population-studies / index.html (accessed 4 February 2015).

16 Bunce C, Wormald R. Causes of blind certifications in England and Wales: April 1999-March 2000. Eye 2008; 22: 905-911.

17 Bunce C, Xing W, Wormald R. Causes of blind certifications in England and Wales: April 2007-March 2008. Eye 2010; 24 1692-1699.
18 Dept. Trade and Industry. 24th (final) report of the home and leisure accident surveillance system. Dec 2003. http:// www.hassandlass.org.uk/reports/2000_2002.pdf (accessed 4 February 2015).

19 Home Safe Home. Report on Home Accidents in Scotland. December 2010. http://www.instituteofhomesafety.com/ articles/HomeAccidentsScotland.pdf (accessed 4 February 2015).

20 NICE guidelines, CG161, June 2013. Falls: The assessment and prevention of falls in older people guidance.nice.org.uk/cg161 (accessed 4 February 2015).

21 Health and Safety Executive. http:/ /www.hse.gov.uk/ legislation/ (accessed 4 February 2015).

22 Health and Safety Executive Annual Statistics Report for Great Britain 2012-13. http:/ /www.hse.gov.uk/statistics/ overall/hssh1213.pdf (accessed 4 February 2015).

23 Scottish Health Survey 2003. Summary of Key Findings. ISBN 075594782 2. Scottish Government, 2005. http:/ / www.scotland.gov.uk/Resource/Doc/924/0021055.pdf. (accessed 4 February 2015).

24 Scottish Health Survey: Topic Report UK Comparisons ISBN 9780755995646. August 2010. Table 3.2. http://www. scotland.gov.uk/Publications/2010/08/31093025/0 (accessed 4 February 2015).

25 Health and Social Care Information Centre. Hospital Episode Statistics, Admitted Patient Care. http://www. hscic.gov.uk/searchcatalogue?q=title $\% 3 \mathrm{~A} \% 22 \mathrm{Hospital}$ +Episode+Statistics \%2C+Admitted+patient+care++England $\% 22 \&$ area $=\&$ size $=10 \&$ sort=Relevance (accessed 4 February 2015).

26 Guly CM, Guly HR, Bouamra O, Gray RH, Lecky FE. Ocular injuries in patients with major trauma. Emerg Med J 2006; 23: 915-917.

27 Scruggs D, Scruggs R, Stukenborg G, Netland PA, Calland JF. Ocular injuries in trauma patients: an analysis of 28,340 trauma admissions in the 2003-2007 National Trauma Data Bank National Sample Program. J Trauma Acute Care Surg 2012; 73: 1308-1312. 